\title{
Minimal fixations for treatment of closed segmental fractures of tibial shaft in adults
}

\section{Introduction}

Fractures of the shaft of the tibia cannot be treated by a simple set of rules. By its very location the tibia is exposed to frequent injury. ${ }^{1}$ Segmental fractures define as; at least two fracture levels (bifocal, trifocal), separating one or several intermediate fracture fragments of tubular bone with intact circumferential cortex of intermediate segments, (AO type 42-C2) ${ }^{2}$ often occur after a high energy direct trauma with consecutive severe soft tissue injury and a high energy fractures. Every fracture is an individual problem because ofthe blood supply of the intermediate bone fragment can be severely disturbed, and therefore the decision to treat it by internal fixation or, indeed, conservatively should be based on a realistic assessment of the advantages and the hazards of each method in the circumstances of that particular case. This calls for a high degree of clinical judgment, which is harder to acquire, or to impart, than technical virtuosity in the operating theater. The indications for operative and non-operative treatment of tibial shaft fractures have not been well defined. ${ }^{3}$

\section{Patients \& methods}

From April 2009 to January 2014, we received 91 patients with high-energy fractures of tibial shaft at orthopedic department of AlRamadi Teaching hospital. 20 patients were suitable for our study and their closed fractures meeting the $\mathrm{AO}$ classification criteria for segmental type: fracture of the tibia presenting two distinct shaft fractures isolating a cylindrical cortical segment measuring several centimeters (42-C2). Those excluded from our study, are shown in Table 1 . There were $17(85 \%)$ men and $3(15 \%)$ women, who sustained $12(60 \%)$ fractures of the right tibia and $8(40 \%)$ fractures of left tibia. The average age of the patients was 43 years (range 23 to 62 years). The mechanisms of injury were shown in Table 2 below, mostly due to motorcycle accident, which lead to high-energy fractures of tibial shaft. Fractures of tibial shafts were classified according to criteria of $\mathrm{AO} / \mathrm{ASIF}$ classification as type 42-C2.

Table I Cases excluded from the study

\begin{tabular}{ll}
\hline Case & No. \\
\hline Open Fractures & 36 \\
Fractures Other than 42-C2 & 14 \\
Fractures with Neuro-vascular Injuries & 2 \\
Fractures with Compartment Syndrome & 4 \\
Fractures with incomplete follow up & 3 \\
Age Below 20 years & 7 \\
Fractures Associated with other Injuries & 5 \\
Total & 71 \\
\hline
\end{tabular}

Volume 2 Issue 5 - 2015

\author{
Ayyoub A Mohammed,' Mohanad H Hasan, ${ }^{2}$ \\ Rami Ahmed ${ }^{3}$ \\ 'Department of Surgery,Al-Anbar University, Iraq \\ ${ }^{2}$ Al-Ramadi Teaching Hospital, Iraq \\ ${ }^{3} \mathrm{Al}-$ Hilal Private Hospital, Iraq
}

Correspondence: Ayyoub A Mohammed, Department of Surgery, College of Medicine, Al-Anbar University, Iraq, Tel +9647700008596, email ayyoub1973@yahoo.com

Received: May 13,2015 | Published: June 6, 2015

Table 2 Mechanisms of injury

\begin{tabular}{lll}
\hline Mechanisms of Injury & No. & $\%$ \\
\hline Motor Cycle Accident & I & 55 \\
Pedestrian Motor Vehicle Accident & 4 & 20 \\
Being Struck By an Object & 3 & 15 \\
Motor Vehicle Accident & $\mathrm{I}$ & 5 \\
Sport Injury & $\mathrm{I}$ & 5 \\
Total & 20 & 100
\end{tabular}

These fractures associated with soft tissues injury were classified according to Oestern \& Tscherne. ${ }^{4}$ The operation was performed with the patient under general anesthesia, on a radiolucent operating table, and under fluoroscopic control. An initial reduction done by manual longitudinal traction and then through minimal skin incision and dissection over proximal and distal fracture sites reduction and alignment obtain and fixed by inter-fragmentary lag screws +/- small plate. Then, we apply a uni-plane external fixator (AO or Thikary type of external fixator) by insertion of 2-3 pins in the upper part of tibial shaft antero-medially and 2-3 pins in the lower part with sparing the fractured segment. We used this mode of treatment as alternative to intramedullary locked nailing where there is no such treatment modality, which is the best option for these types of fractures (Table 3).

The operation was done within 48 hours after injury in $11(55 \%)$ patients and in the remaining $9(45 \%)$ patients, it was delayed for a period of elevation of the injured limb and observation and keep splinted by either above knee plaster $6(30 \%)$ patients or a longitudinal skeletal traction through a calcaneal Steinman pin $3(15 \%)$ patients, and the reasons for elevation to relieve soft tissue swelling or blistering or both, then operation done 7-10 days later on.

Postoperatively, patients were managed with a first generation cephalosporin 2-3 days. All of the injured limbs (postoperative) were 
elevated until swelling of the soft tissues had resolved. Tight wraps were kept on both the proximal and distal pin clusters for 5-7 days. Physical therapy was initiated on second to the fifth postoperative day. This physical therapy depends on:
1. Security of fixation.
2. Presence of soft tissue injury.
3. Concomitant injuries.
4. Patient compliance.

Table 3 Collecting data of the twenty patients

\begin{tabular}{|c|c|c|c|c|c|}
\hline \multirow[t]{2}{*}{ Case } & \multicolumn{2}{|c|}{$\begin{array}{l}\text { Angulation in } \\
\text { Degree }\end{array}$} & \multirow{2}{*}{$\begin{array}{l}\text { Rate of } \\
\text { Union } \\
\text { Weeks }\end{array}$} & \multicolumn{2}{|l|}{ Infection } \\
\hline & Coronal & Saggital & & Superficial & Deep \\
\hline 1 & 0 & 3 & 18 & $+\mathrm{ve}$ & -ve \\
\hline 2 & 2 & 1 & 12 & -ve & -ve \\
\hline 3 & 4 & 2 & Non-union & -ve & -ve \\
\hline 4 & 1 & 0 & 14 & -ve & -ve \\
\hline 5 & 3 & I & 16 & -ve & -ve \\
\hline 6 & 4 & 0 & 18 & +ve & -ve \\
\hline 7 & I & 1 & 16 & -ve & -ve \\
\hline 8 & 0 & 2 & 12 & -ve & -ve \\
\hline 9 & I & 2 & 14 & -ve & -ve \\
\hline 10 & 3 & 0 & 16 & -ve & -ve \\
\hline 11 & 1 & 3 & 26 & $+\mathrm{ve}$ & -ve \\
\hline 12 & 2 & 0 & 16 & -ve & -ve \\
\hline 13 & 3 & 0 & 14 & -ve & -ve \\
\hline 14 & 0 & 1 & 14 & -ve & -ve \\
\hline 15 & I & 3 & 18 & $+\mathrm{ve}$ & -ve \\
\hline 16 & 0 & 2 & 28 & $+v e$ & -ve \\
\hline 17 & 2 & 2 & 12 & -ve & -ve \\
\hline 18 & 0 & 1 & 16 & -ve & -ve \\
\hline 19 & 2 & 1 & 14 & -ve & -ve \\
\hline 20 & 0 & 1 & 18 & $+\mathrm{ve}$ & -ve \\
\hline
\end{tabular}

Also, partial weight bearing was allowed according to above factors. Alignment and healing of the fractures were followed with clinical examination and serial radiographs 2 weekly. The fixator was converted to a dynamic construct (the axial locking nut on the slider body was released) 8-10 weeks after the injury and the patient was allowed to progress to full weight bearing at this time. The fixator remained in place until the fracture had healed clinically and radiologically. Then, we do a trial of removal of the body of the fixator and before the fixator pins were taken out, we asked the patient to walk. If there was pain at the fracture site, the body of the fixator was re-placed and was worn for an additional 4-6 weeks. If there was no pain, we remove the pins and change the fixator to below knee walking cast for 2 weeks and then check.

\section{Follow up was assessed by the following parameters:}

1. Rate of union.

2. Alignment.

3. Infection.

\section{The rate of union}

This parameter was assessed clinically and radiologically. Clinical criteria for union of the fracture were the absence of pain both with manual loading (in a bending mode of the fracture) and during full weight bearing with the fixator bar removed but the pins left in place. The radiographic criteria for union were defined as the presence of bridging callus as seen on the follow-up radiographs. Fractures of tibial shaft united within 12-24 weeks. Delayed union was defined as lack of union after 24 weeks after the injury. Non-union was defined as lack of union more than 32 weeks. ${ }^{5-7}$

\section{Alignment}

Angulation was measured in the latest follow up visit. Malunion was defined as more than 5 degrees of mal-alignment in any plane. Varus or valgus angulation was measured on antero-posterior radiographs and anterior or posterior angulation (angulation in the sagittal plane) on lateral radiographs by using a goniometer and CT scan. 5,7

\section{Infection}

Was divided into, superficial pin track infections involving only the soft tissue of the tract without bony involvement, and deep pin tracts infection leading to osteomyelitis ${ }^{6,7}$.

\section{Examples of cases}

a. Case 1: Displaced lower 1/3rd segmental tibial shaft fracture. Treated by 3 screws + external fixation (Figure 1 ).

b. Case 2: Displaced middle 1/3rd segmental tibial shaft fracture. Treated by upper fracture site by mini-plate $\&$ lower fracture site by fragmentary screws + external fixation (Figure 2).

c. Case 3: Displaced middle 1/3rd segmental tibial shaft fracture + fracture medial malleolus. Treated by mini-plate $\&$ fragmentary screws + external fixation (Figure 3 ). 


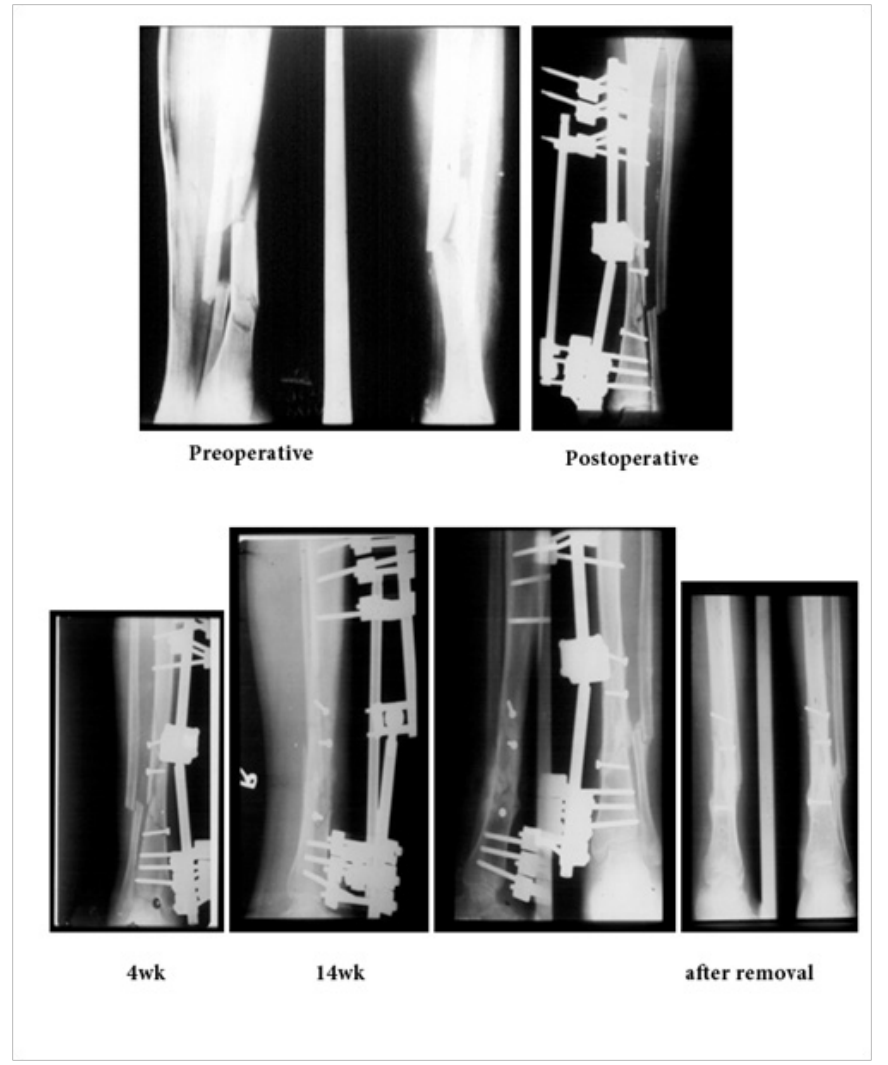

Figure I Case - I Displaced lower I/3rd segmental tibial shaft fracture.

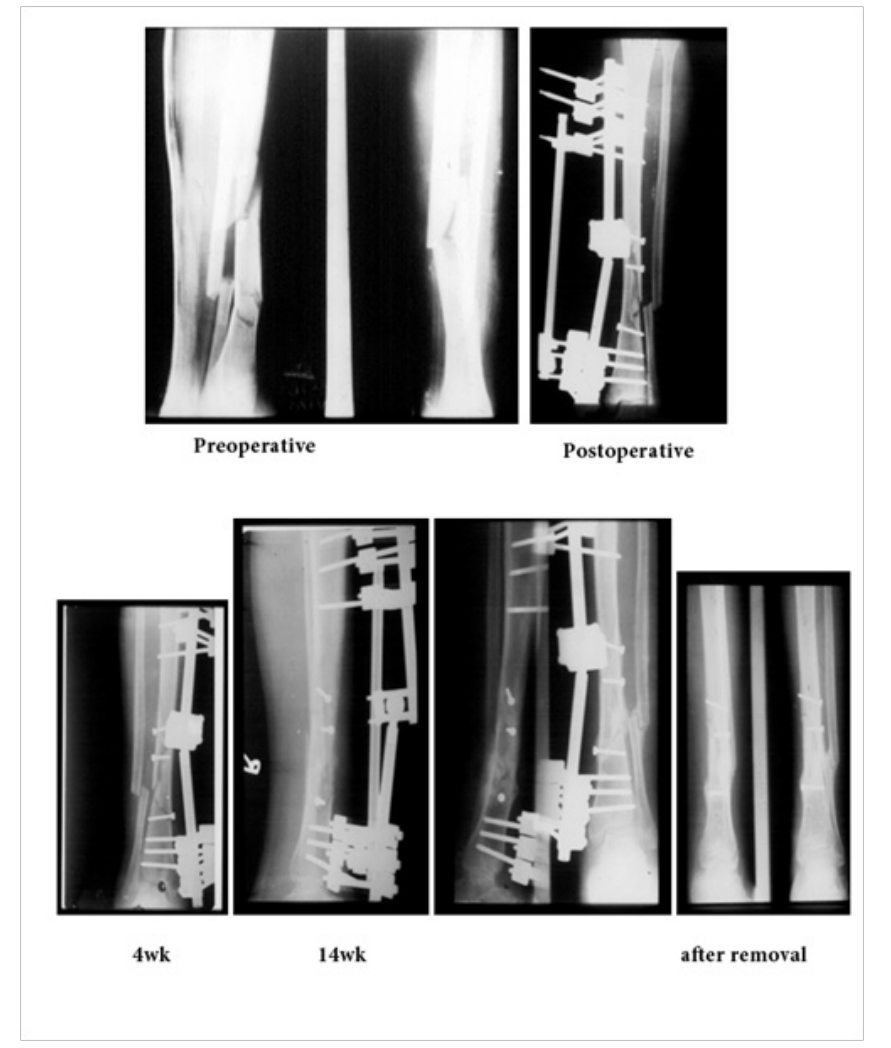

Figure 2 Case 2 - Displaced middle I/3rd segmental tibial shaft fracture. 


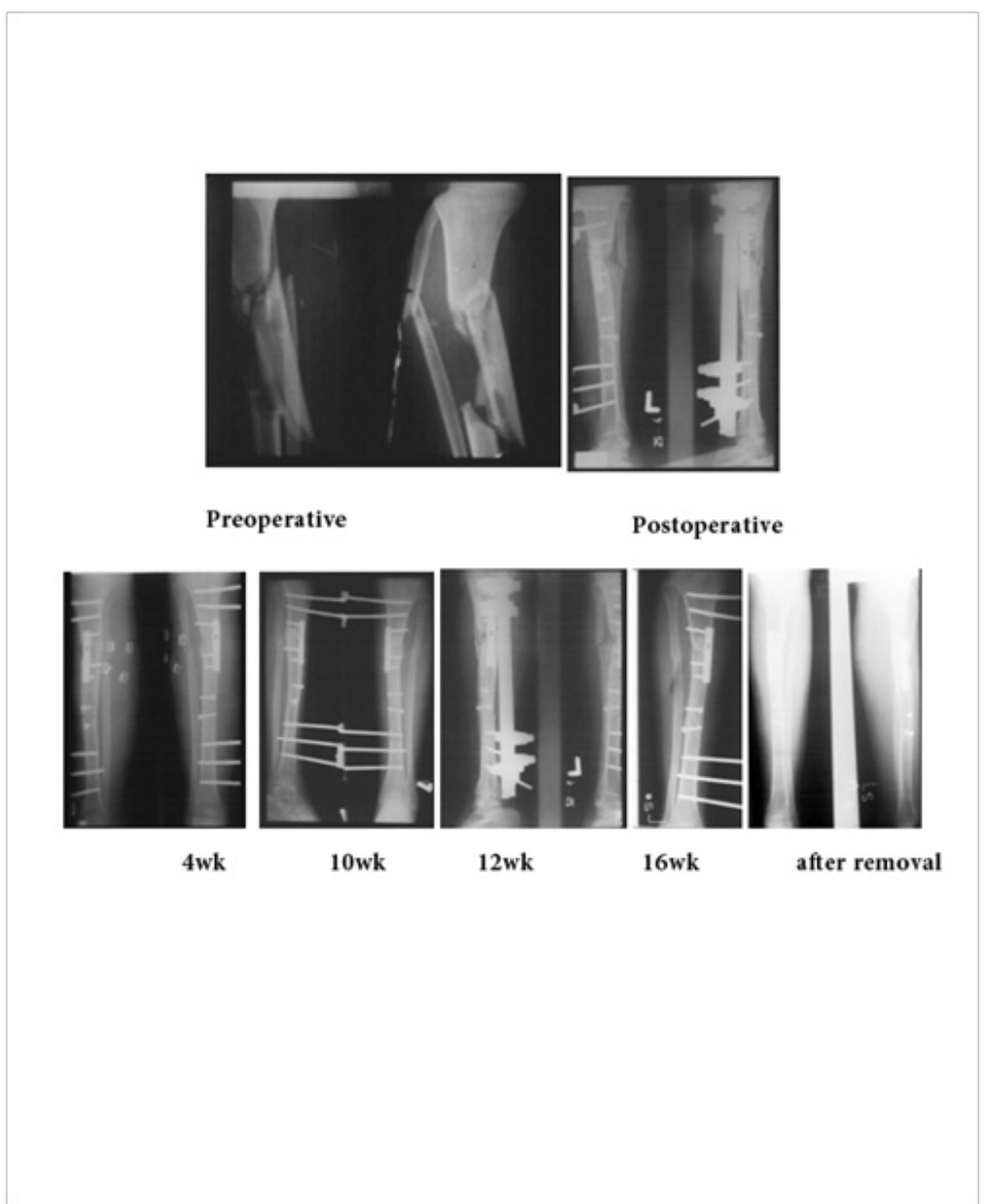

Figure 3 Displaced middle I/3rd segmental tibial shaft fracture + fracture medial malleolus.

\section{Results}

The duration of hospitalization averaged 10-15 days. 19 (95\%) fractures healed without additional procedures. The average of duration of external fixation was 16 weeks (range 12-26 weeks). The time of union judged both clinically and radiologically averaged 16 weeks (range 12-30 weeks). There were $17(85 \%)$ fractures pass to sound union within $12-20$ weeks. Two $(10 \%)$ fractures progress to delayed union and take 26-28 weeks to unite without any surgical interference. And only one case (5\%) passes to non-union in the distal fracture site after 32 weeks of our treatment, which may be due to:

1. The distal site fracture is more prone for healing problems.

2. Patient not follows our instruction given to him (impossible patient).

The problem solved by addition of bone grafts to the nonunion site without changing the fixation device. All the united fractures were aligned with less than 50 in either coronal or sagittal plane and without any rotational mal-alignment. There were $6(30 \%)$ cases suffering from superficial pin tracts infection which presented with pain and cellulites around the pin tracts with some discharge from the sites and staphylococcus aureus grew on culture of discharging swap, and patients treated by ciprofloxacin orally, while the fixator was in place and for 1-2 weeks after removal of the fixator with meticulous local hygiene. No patient from those passes to full picture of osteomyelitis.

\section{Discussion}

Indeed any high-energy fractures, including segmental fractures, which are inherently unstable require early surgical stabilization, and conservative treatment of such fractures has proven to be inferior when compared with operative treatment with regards to the duration of hospital stay, the need of immobilization, and the functional results carries high risk of delayed union and Malunion. ${ }^{5,6}$ Fracture healing is theoretically enhanced by anatomical reduction, preservation of blood supply and sufficient stable internal and external immobilization. ${ }^{7}$

Operative treatment of segmental tibia fractures is challenging even for the experienced surgeon. The combination of periosteal damage and the destruction of the endomedullary blood supply will be responsible for bone healing problems. ${ }^{8-10}$ They occur in up to $29 \%$, more frequently in the distal fracture site. ${ }^{8,9,11,12}$ Intramedullary nailing is widely accepted as the treatment of choice for uncomplicated tibia shaft fractures. ${ }^{13-16}$ But there is high rate of bone healing problems after intramedullary nailing of segmental fractures which is explained by the frequent use of the unreamed tibial nail as implant of choice. The small diameter of this nail, the small diameter of the interlocking screws, the parallel insertion of both proximal interlocking bolts and the toggling of the bolts in the interlocking holes of the nail all are responsible for the low intrinsic stability of the construct. In many cases, stability in the fracture sites is too low for uneventful fracture healing. ${ }^{17,18}$ 
Optimal reduction and good stability even in complicated fractures can be achieved with plates and screws osteosynthesis. In many other articles, plate and screw osteosynthesis shows bone-healing problems in about $6-25 \% .{ }^{8,10,12,19}$ The most important danger of plate fixation is the surgical exposure of the intermediate fragment, which can additionally damage the already compromised blood supply. Other treatment modality is the external fixation but this carry highest rate of nonunion and pseudoarthrosis. ${ }^{8-10}$ But the advantages of external fixation are the less affection of the soft tissue and the easier technical approach compared to intramedullary nailing. The insertion points of the pins can be placed at a distance from damaged soft tissues. Therefore, external fixation often is used in fractures with severe soft tissue damage and poly-trauma patients with complex fractures. In our series, we try to combine the advantages of those treatment options to get this simple effective method of treatment.

Non-union rates by using inter-locked nailing was reported in some series to be about $3 \%,{ }^{20}$ and one in three for unlocked nailing ${ }^{8}$ and $4.1 \%$ in other methods of fixation. ${ }^{10}$ In our work the non-union rate was $(5 \%)$ and the healing problem occurs at the distal fracture site of the intermediate segment. This is explained by the more precarious blood supply of the distal fracture site and the natural tendency to slow union in fractures in this location. ${ }^{8,10,11}$ In addition, those patients not fully respond to our instructions which also a cause of healing problems. Many authors stated that union may be delayed in some cases and could be affect either proximal ${ }^{21}$ or distal fracture sites,${ }^{16}$ but other authors report no difference in union rates. ${ }^{22}$ In our study-delayed union occur in two $(10 \%)$ patients who affect the distal fracture sites in both patients but it progress to union and take 26-28 weeks to unite without any surgical interference. We found that union was quicker in the proximal fracture sites than distal, and more in the postero-lateral part of the tibia than the antero-medial part; this may be due to better blood supply and more soft tissue coverage in this area.

In addition, the duration of use of the external fixator and the time to union of the fracture were decreased, suggesting that the use of minimum osteosynthesis was advantageous in the treatment of these patients. The amount of mal-alignment and shortening considered acceptable is controversial. Trafton's recommendation and strive to achieve less than 5 degrees of varus-valgus angulation, less than 10 degrees of anterioposterior angulation, less than 10 degrees of rotation, and less than $15 \mathrm{~mm}$ of shortening. ${ }^{23}$ In our cases the range of angulation in any plane is equal and less than $4^{\circ}$. This is because of the use of minimal internal fixation and external fixation for achievement and maintenance of an anatomical reduction and improved stability of the fracture in patient who have segmented fracture of tibial shaft 42-C2.

In our series the rate of pin track infection was $10 \%$ and it was superficial type and the patients respond well to oral antibiotics. No patient passes to deep infections or osteomyelitis. So there is a significant reduction in the infection rate in contrast to other authors who report deep bone sepsis in $10-15 \%$ using deferent methods of fixation ${ }^{10,24}$ and this may be due to less soft tissue disruption and shorter operative time needed for our minimal procedures. Biomechanical experiments have shown a major increase in stability of the fracture with the use of minimal internal and external fixation. ${ }^{25,26}$

Initial clinical experience with minimal internal fixation added to minimal external fixation seamed to substantiate the value of enhanced stability of the fractures. ${ }^{27-31}$ In a retrospective study of Scharf et al. ${ }^{29}$ found a decreased need for secondary cancellous bone grafting in patients who were treated by minimal internal fixation. Strummer, in his histological investigations of fracture healing with use of external factors and minimal internal fixation, found primary fracture healing with formation of callus. The fracture gap, however, was bridged by laminar bone, and the rate of fracture healing was good. ${ }^{32}$ Finally, the improved reduction and stabilization gained by our minimally invasive techniques appear to have a favorable on healing of bone and soft tissue in treating these complex fractures to limit the soft tissue and wound complications that have reported after conventional types of fixation.

\section{Conclusion}

Treatment of segmental fractures of the tibia remains difficult and controversial, which must be distinguished amongst tibial fractures because of the different trauma context, the difficulties encountered in establishing a solid fixation, and the slow bone healing. We found the use of uni-plane external fixation with minimal internal fixation to be successful for the management of closed segmented fracture of tibial shaft in presence of more complex fracture and soft tissue injuries in order to decrease operative time with comparable less complication in contrast to other treatment options.

\section{Recommendation}

Form our and other author's results we recommend the use of minimal internal and external fixation in treatment of closed segmented fracture of tibial shaft $(42-\mathrm{C} 2)$ as best alternative to closed reamed interlocking nail.

\section{References}

1. Terry CS, James HB. Tibial shaft fracture. Campbell's operative orthopedics (12th edn), Canada, 2013

2. Müller ME, Allgöwer M, Schneider R, et al. Manual of internal fixation. Techniques recommended by the AO-ASIF Group. (3rd edn), 1991;pp. 144-153.

3. Nicoll EA. Closed and open management of tibial fractures. Clin Orthop Relat Res. 1974;105:144-153.

4. Tscherne H, Gotzen L. Fractures with soft tissue injuries. SpringerVerlag, Berlin, Germany, 1984.

5. Chapman MW. Tibial shaft fractures: Chapman's orthopedic surgery. (3rd edn), 2001.

6. Solomon L, Warwick D, Nayagam S. Principle of fractures (9th edn), Apley's system of orthopedic and fracture. CRC Press, India, 2010;pp. 543.

7. Krettek C, Haas N, Tscherene H. The role of supplemental lag-screw fixation for the tibial shaft fractures treated with external fixation. $J$ Bone Joint Surg Am. 1991;73(6):893-897.

8. Rommens PM, Coosemans W, Broos PLO. The difficult Healing of Segmental Fractures of the tibial shaft. Arch Orthop Trauma Surg. 1989;108(4):238-242.

9. Rommens PM, Broos P, Gruwez JA. Nachuntersuchungsergebnisse von 102 mit DC-Plattenosteosynthese stabilisierten Tibiaschaftfrakturen. Unfallchirurgie. 1986;12(6):320-326.

10. Giannoudis PV, Hinsche AF, Cohen A, et al. Segmental tibial fractures: an assessment of procedures in 27 cases. Injury. 2003;34(10):756-762.

11. Melis GC, Sotgiu F, Lepors M, et al. Intramedullary nailing in segmental tibial fractures. J Bone Joint Surg Am. 1981;63(8):1310-1318. 
12. Rhinelander FW. Tibial blood supply in relation to fracture healing. Clin Orthop Relat Res. 1974;105:34-81.

13. Hansen M, Gercek E, Blum J, et al. Osteosynthetische Versorgung proximaler extraartikulärer tibiafrakturen. Unfallchirurgie. 1999;25(34):174-182.

14. Johner R, Wruhs O. Classification of tibial shaft fractures and correlation with results of rigid internal fixation. Clin Orthop Relat Res. 1983;178:724.

15. Mommsen U, Stammer HJ, Junbluth KH. Der Unterschenkeletagenbruch. Unfallchirurgie. 1980;6(3):178-182.

16. Langard O, Bo O. Segmental tibial shaft fractures. Acta Orthop Scand. 1976;47(3):351-357.

17. Ekeland A, Thoresen BO, Alho A, et al. Interlocking intramedullary nailing in the treatment of tibial fractures-a report of 45 cases. Clin Orthop Relat Res. 1988;231:205-215.

18. Hansen M, Mehler D, Rommens PM. Das biomechanische Verhaltenwinkel stabiler Implantat system eander proximalen Tibia. Verlag Hans Huber, Switzerland, 2004.

19. Hansen M, Mehler D, Hessmann MH, et al. Intramedullary stabilization of extraarticular proximal tibial fractures: a biomechanical comparison of intramedullary and extramedullary implants including a new proximal tibia nail (PTN). J Orthop Trauma. 2007;21(10):701-709.

20. Wu CC, Shih SH. Segmental tibial shaft fractures treated with interlocking nailing. J Orthop Trauma. 1993;7(5):468-472.

21. Huang CK, Chen WM, Chen TH, et al. Segmental tibial fractures treated with interlocking nails. A retrospective study of 33 cases. Acta Orthop Scand. 1977;68(6):563-566.

22. Merianos P, Papagiannakos K, Scretas E, et al. Ender nails for segmental tibial fracture. Early weight bearing in 22 cases. Acta Orthop Scand. 1988;59(3):297-301.
23. Trafton PG. Closed unstable fractures of the tibia. Clin Orthop Relat Res. 1988;(230):58-67.

24. Bonnevialle P, Cariven P, Bonnevialle N, et al. Segmental tibia fractures: a critical retrospective analysis of 49 cases. Rev Chir Orthop Reparatrice Appar Mot. 2003;89(5):423-432.

25. Etter E, Burri C, Kinzl L, Raible M. Belastungs stabilitat in Abhangigkeit von Osteosynthese verfashren, Verlauf und komplikationenbei of fenenunter schenkelfrank turenmit Schwerem Weichteischaden. Aktuelle Traumatol. 1982;12:78-82.

26. Claes L, Burri C, Heckmann G, et al. Biomechanische Unter such ungenzur stabilitat von Tibiaosteosynthse senmitdem Fitateurexterne und einer Minimalosteosynthese. Aktuelle Traumatol. 1979;9:185-189.

27. Burri C, Claes L. Indikation und Formen der Anwendug des Fixateurexterne am unterschenkel. Unfallheilkunde. 1981;84:177-185.

28. Bosse MJ, Staeheli JW, Reinert CM. Treatment of unstable tibial diaphyseal fractures with minimal internal \& external fixation. J Orthop Trauma. 1989;3(3):233-231.

29. Scharf W, Orthner E, Wagner M. Behandlungsrichtlinien, und Ergebnisse Schwerst Offener Unterschen kelbruche. Unfallchirurgie. 1984;10:192199.

30. Schottle H, Schontag H, Langendorff HU, et al. Ergbniesse der operativenstabilisierungbei: 307 offenenFRakturen. Unfallchirbugie. $1981 ; 7(5): 256-259$

31. Spiegel PG, Vanderschilden JL. Minimal internal and external fixation in the treatment of tibial fractures. Clin Orthop. 1983;178:96-102.

32. Sturmer KM. Histomorphologie der Frakturheilung im vergleich der fixationsverfahren am Tibial shaft. In: Schmit-Neuerburg KP \& Sturmer KM (Eds.) Die \& Tibaschaftf rakturbeim Erwachsenen. Springer, New York, USA, 1987;pp. 23-49. 